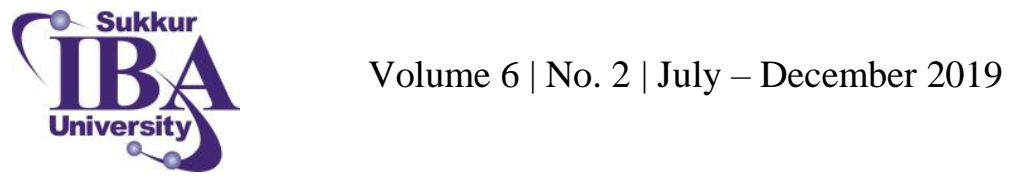

Sukkur IBA

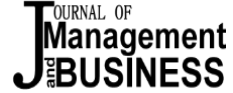

P-ISSN: 2313-1217

E-ISSN: 2410-1885

\title{
Adoption of Reverse Logistics in Food Companies: A Case of
}

\section{Pakistan}

\author{
Kamran Rashid $^{1}$, Shaheer Malik ${ }^{1}$, Maimoona Waseem ${ }^{1}$
}

\begin{abstract}
:
This research highlights the importance of Reverse Logistics in Food Companies and explains its implementation level in food companies of Pakistan. Reverse Logistics is the process by which products are brought back to the producer due to some problem in the products. This study describes how food companies are dealing with returned items, their packaging material waste and the food and packaging material waste created at the consumers' end. The other significant aspect of this research is the exploration of hindrances due to which companies do not perform the activities of RL especially in food companies. This study has focused on two local food companies operating in Lahore, mainly dealing in confectionary items such as breads, patties etc., sweet meats, soft drinks and milk. The research has employed Semi structured interviews as a tool to gather data which is then analyzed using NVIVO software. The results have shown that both of the companies have implemented different aspects of Reverse Logistics and the problems they face while developing a Reverse Logistics process are more or less the same. This study would be forerunner in highlighting the current status and the problems faced by the companies.
\end{abstract}

Keywords: Reverse logistics, Pakistan Food companies, food waste, food recycling.

\section{JEL Classification: M3}

\section{Introduction}

In this competing world, every company is striving to get ahead of each other. The everyday technological advancements and the ever-increasing pressure for providing the best product has compelled companies to develop innovative ways to achieve that next level position. One of the most effective ways of doing this is to explore innovative options for handling waste materials. Reverse Logistics is gaining importance as a vital instrument for gaining economic advantages and a better social image because a proficient reverse logistics process can result in a competitive advantage (Liobikiene and Dagiliute 2016; Markaki et al. 2017). Reverse Logistics can be used for coping up with resource depletion and environmental problems while encouraging sustainable

${ }^{1}$ Department of Operations and Supply Chain, School of Business and Economics, University of Management and Technology, Lahore, Pakistan

OPEN This work is Licensed under a Creative Commons Attribution-Noncommercial 4.0 International License c) (i) (8)


development (Liu 2014; Das and Chowdhury 2012; Sun et al. 2015). The increased environmental awareness and environmental laws have forced the companies to handle waste materials in an environment friendly way. Furthermore, returned products have a higher potential of cost recovery and to reclaim monetary benefits. This is why it is necessary to have a reverse logistics mechanism which could handle returns and waste materials efficiently.

Different definitions of Reverse Logistics are available, but the main theme is common. The council of Logistics Management has defined Reverse Logistics as "It is the process of planning, implementing and controlling the efficient, cost effective flow of raw materials, in process inventory, finished goods and related information from the point of consumption to the point of origin for the purpose of capturing value or proper disposal". According to Hazen et al. (2015), Reverse Logistics is the movement of items from the consumer side in the direction of the producer in a distribution channel. In Reverse Logistics process, a product returns to the manufacturer after its lifecycle has completed and can be used again to make other items and can be sold to end consumers (Choudhary et al. 2014; Coskun et al. 2016; Diabat and Salem 2015; Fahimnia et al. 2015; Godichaud and Amodeo 2015). "Reverse Logistics is the flow of products in a direction that is opposed to customary logistics with the aim of recollecting value or to dispose off the products in the proper ways (Demirel et al., 2014; Das and Dutta, 2013; Tibben-lembke and Rogers, 2002)". Reverse Logistics begins where the forward supply chain completes. In Reverse Logistics, the manufacturer looks out after the returns process and the items are recovered directly or by indirect networks (Ashayeri, Ma \& Sotirov, 2015)

Reverse Logistics helps in the development of a Green and Sustainable Supply Chain. For an effective Green Supply Chain Management, it is necessary that the flow and reprocessing of materials should be done effectively and efficiently and the recycled material should be included in the main manufacturing stream. (Olugu et al., 2010b; Nunes et al., 2009)

It is really necessary to manage the end of life products not just because of the increasing amount of solid waste but also because of the economic advantages and legislative issues (Demirel et al. 2014; Das \& Dutta (2013)). Many a time companies focus their energies and assets to forward operations forgoing the value that reverse operations can provide which are sometimes necessary for a company to survive (Bernon, Rossi and Cullen, 2010). In the recent years, reverse logistics has gained an important place in the global competition, compelling companies to adapt a number of policies and practices. This has resulted in the optimization of reverse logistics processes by taking care of financial, environmental and regulatory issues which make it a rapidly evolving research field (Xanthopoulos et al., 2012, de Brito, 2004).

Forward logistics strategies are not applicable to reverse logistics because there exists a large difference between them. The problems which fail the forward logistics mechanisms in handling reverse movement are difficulty in product forecasting, requirement of special equipment at a number of distribution centers and the uncertainty in product life cycle (Vaidyanathan and Yadong, 2007; Pokharel and Mutha, 2009).

Sukkur IBA Journal of Management and Business - SIJMB | Vol 6 No. 2 July - December 2019 ๑ Sukkur IBA University 
Reverse Logistics is required in the food industry to provide quality and safe food to consumers without posing any threat to human life and the environment. The major factors which necessitate the use of reverse logistics in food industry are volatile food markets, shorter product lifecycles, return of faulty products, failure to comply with good manufacturing norms, not maintaining food processing facilities and equipment, not complying with SOPs and environmental laws.

The food industry has perishable nature of items due to which there is always a chance of products returning to the manufacturer i.e. Food Recalls. The other thing concerning the food companies is the food waste which should be dealt in an efficient way. Another important issue in the Food industries is the packaging material waste of the food items which must be dealt by the manufacturer to fulfill his duty towards the society and environment. Due to these aspects there is a need that food companies must possess a structured mechanism which could handle the product recalls (products returning to manufacturer), product wastes and the packaging material.

This study focuses on exploring the application of reverse logistics activities in Pakistan's food industry. The Pakistani Food industry is expanding. There are many companies in the market which are competing against each other for only 1 food item and there are numerous food items in the market. The food industry of Pakistan has 4 phases: production, process, transportation, and distribution. Thus it involves everyone from a small farmer to a retail distributor. The food industry has employed more than $20 \%$ of country's working population. In the recent years there has been a great boom in the food industry of the country. According to the Chambers of Commerce and Industry there are about 168 notable food companies dealing in different types of food items. Big names in the food industry include Nestle, Pakistan food and beverage company, Unilever Pakistan, etc. Other than these names there are companies like Shan Foods, Gourmet Foods, National Foods, and K\&Ns etc.

Just like other developing countries, Pakistan is facing environmental issues. No planned drainage systems, not enough human and financial resources for collecting and disposing off wastes, no availability of official dumping sites and almost no availability of recycling processes have adversely affected waste management in our country. Solid waste management companies which are operated by government collects only about $50 \%$ of waste generated. Around 0.283 to $0.612 \mathrm{~kg}$ per capita per day waste is generated in Pakistan (Ministry of Environment, 1996). The food waste accounts for about 8.4\% to $21 \%$ whereas recyclable materials account for about $13.6 \%$ to $23.55 \%$ of the total solid waste generated in Pakistan. In Pakistan, the town municipal administrations are responsible for collection, transportation and disposal of Solid waste, but due to lack of expertise, lack of funds and standards, they are unable to cope up with the increasing amount of waste generated.

The purpose of this study is to gain an insight on what are the barriers due to which companies don't use Reverse Logistics. No substantial data is available on reverse logistics especially in food companies. So, this study will be a forerunner in highlighting the reasons or difficulties companies face while implementing reverse logistics.

Reverse Logistics has been risen as an important aspect in business. With companies

Sukkur IBA Journal of Management and Business - SIJMB | Vol 6 No. 2 July - December 2019 @ Sukkur IBA University 
focusing on specialized reverse logistics activities globally, it has become a hot topic among practitioners as well as academia. Neglecting reverse Logistics can cause a reduction in the value which a firm may gain from returned products, can have a bad impact on the relationships with customers and there is a chance that it can increase the cost of reverse logistics activities due to inefficient attention of management on the process (Souza et al., 2006).

This research will help companies to understand the importance and identify the benefits, both monetary and social, that Reverse Logistics could provide them. This study will guide them about the pre-requisites to develop a Reverse Logistics process or enhance their performance if they are already performing certain activities of Reverse Logistics.

Moreover, as there is less literature available specifically on Reverse Logistics in food companies, this research will guide future researchers to better understand the condition of Reverse Logistics in food companies and devise better solutions for the problems that companies face while implementing Reverse Logistics

The research aims to address the following questions:

Q.1 How Local Food Companies in Pakistan are handling returns? What do they do with the returns?

Q.2 What are the barriers to the implementation of Reverse Logistics processes in food companies?

\section{Literature Review}

\subsection{Reverse Logistics}

According to the Reverse Logistics Association, Reverse Logistics is defined as "all activities associated with a product/service after the point of sale, the ultimate goal of which is to optimize or make more efficient aftermarket activity, thus saving money and environmental resources". A reverse logistics process starts when the consumer has decided that the product has completed its life and now it needs to be disposed of (Blumberg, 2005).

The main activities involved in Reveres Logistics include Product acquirement and collection, examination and categorization and disposition (Niknejad and Petrovic 2014; Agrawal et al. 2015; Farhani and Ozturk 2015; Ali et al. 2016). The collected products can be useful in various ways such reusing, selling to other markets, repairing, refurbishing, remanufacturing, recycling and if not possible then disposing it off is the only option available.

Reverse Logistics players comprise of manufacturers, distributors, wholesalers and retailers. Beside these there are some additional players in RL process who are experts in this area. These include 3PLs (De Briton \& Dekker, 2003; Efendigil et al., 2008), brokers, jobbers (Efendigil et al., 2008) and intermediate processors (Krikke 1998).

The 3PLs are used when a company wants to outsource their reverse logistics activities. Brokers buy the returned products at a very low price and sell them to secondary markets (Rogers and Tibben-Lembke, 1998). Jobbers are the entities which buy returned products from retailers and after repairing they sell them to consumers or 
intermediaries (Bernon et al., 2011). Intermediaries are somewhat similar to jobbers. They buy the recyclable materials and after performing certain operations on them sell them to manufacturers (Krikke, 1998).

For a successful Reverse logistics system, it is necessary that all people involved must be aware of its importance and how it works. Due to the uncertainty in the timing and quality of returned products, specialized networks, handling systems and information processing systems are needed (KO and Evans, 2007). This difficulty of forecasting returns is due to the fact that there are a lot of suppliers i.e., consumers when talking about returned products. Moreover, all the returned products do not have the same conditions.

All the municipal solid waste practices are basically Reverse Logistics Operations, which are of great importance in the developed world. Solid waste management is a very important topic under consideration globally and apprehensions about it have been continuously on the rise since the 1990s (Kannan et al., 2014). A number of studies have identified the need to reduce the quantity of solid waste which is being dumped in landfills and increasing the reusage of material after its lifecycle has ended (Lederer et al., 2015; Danubianu and Teodorescu, 2015; Gutberlet, 2008). When these MSW (municipal solid waste) management practices are done efficiently, they can result in improved levels of recycling and reduced amounts of MSW to be disposed off in landfills or incineration (Beullens, 2004; McLeodet al., 2008). The municipal Reverse Logistics providers are dedicated to reduce the amount of MSW sent to landfills by efficient waste recovery techniques (Dovidio, 2013).

Reverse Logistics has been viewed as both a business enhancing process as well as a step towards fulfilling the corporate social responsibility of the company. Environmental and economic issues are the major driving forces for Reverse Logistics. This results in a closed loop supply chain system which means that the forward supply chain is accompanied with Reverse operations by which the returned products are reprocessed. Many researches have shown that the application of reverse logistics can result in many benefits which include having a greater position in the market due to a lot of cost saving (Jack et al., 2010; Srivastava and Srivastava, 2006), an increase in profit (Nidumolu et al., 2009; Alfonso-Lizarazo et al., 2013; Das and Dutta, 2013), increase in satisfaction of customer (Li and Olorunniwo, 2008; Richey et al., 2005) and a reduction in environmental impact (Sundarakani et al., 2010; Lai et al., 2013).

The company producing a certain product is the master of its fate after its lifecycle. The decision of whether a product is economically beneficial to recover depends on the firm. Buellens (2004) says that a company who wishes to adopt a reverse logistics process might overcome the technical and legal problems but it is the cost that may demotivate them. Although if resources are efficiently used to develop innovative ways to handle returns, then the RL process can be beneficial (Richey et al., 2005). By implementing Reverse Logistics, a company cannot only gain economic advantages such as cost savings in inventory and waste disposal but also results in improved customer loyalty (Kannan et al., 2012). .The economic advantage occurs due to the recycling of products while environmental benefits by the reduction of solid waste pollution (Ginter and

Sukkur IBA Journal of Management and Business - SIJMB | Vol 6 No. 2 July - December 2019 @ Sukkur IBA University 
Starling, 1978), landfill saturation (Kroon and Vrijens, 1995) or preservation of raw materials (Ginter and Starling, 1978). Nagel and Meyer (1999) in their research have devised a procedure that systematically models the end of life networks of products and have also put light on ways by which existing and new systems can be made better keeping in view the ecological and economical aspects.

A successful RL system enhances the public image of the company. It can help a company to increase its sales. When customers face no hassle in dealing with returns, they are more willing to complete the initial sale. (Daugherty, Myers \& Richey, 2002; pp. 86). Firms which do not appreciate the importance of Reverse Logistics do not only risk relationship with customers but also jeopardize the company's name and brand image (Fleischmann et al. 2003; Stock et al. 2006).

Consumers as well as manufacturers are unaware of the benefits Reverse Logistics can reap (Ravi and Shankar 2015). Similarly, they are unaware of the adverse effects caused by the absence of RL. A lot of cost saving can be done when a company has implemented a successful RL mechanism. There is a cost saving of about $40-60 \%$ by remanufactured products in comparison to making new products from scratch and it saves about $85 \%$ of the energy used because due to remanufacturing the life cycle of the product is stretched (Kumar and Putnam, 2008). Petersen and Kumar (2009) have estimated that rate of returns is greater than $25 \%$ of total sales which is approximately $\$ 100$ billion in lost sales in U.S. which leads to a profit reduction of 3.8\% per retailer or manufacturer. A firm's performance can be evaluated by the extent of its involvement in RL activities. Nikolaou, Evangelinos and Allan (2011) reported that firm performance is gauged by economic sustainability and they have presented many sustainability indicators such as sales of reuse, resalable and recyclable, cost of returned materials, and subsidies associated to reverse logistics. Keeping in view such statistics, companies have become aware of the importance of reverse logistics. Quite a large number of books and case studies have been presented in many industries which presents variety of recovery options (Guide and van Wassenhove, 1999; De Brito et al., 2005; Flapper et al., 2005). Companies like Dell, AT\&T, Sony, Lenovo, Siemens and Nokia have worked a lot towards the collection of e-waste and recycling programs (Kang and Schoenung 2005; Kahhat et al. 2008; Nnorom and Osibanjo 2008; Yu et al. 2010; Govindan and Popiuc 2014; Esenduran and Kemahlıg lu-Ziya 2015). Xerox, for example, has developed an efficient reverse logistics process from product development to recovery or disposal (Maslennikova and Foley, 2000). Recellular, a mobile phone company, remanufacture mobile phones and generates a good amount of money from it (Guide and Van Wassenhove, 2003). Duhaime et al. (2000) discuss the distribution and collection of returnable containers by Canada Post. Companies like Eastman Kodak and Hewlett-Packard have used reverse logistics which has been proved beneficial for them (Marien, 1998). Haier group in 2007 created a recycling center in Qingdao where about 200000 used home appliances e.g. TVs, washing machines and ACs can be recycled (Lai et al., 2013). Similarly, IBM introduced an IBM Sterling RL with the help of which the company could keep a track of items through the return and repair process which enabled to return items to stock and classify the item as refurbished automatically

Sukkur IBA Journal of Management and Business - SIJMB | Vol 6 No. 2 July - December 2019 ๑ Sukkur IBA University 
(IBM, 2014). RL has become a profitable business for many entities. NGOs should consider Reverse Logistics from a business perspective and convert this into a profitable business (Seelos \& Mair, 2005; Brugmann \& Prahalad, 2007).

The typical activities which are involved in reverse logistics are: Gate keeping (which products would enter the RL system to avoid unnecessary handling and cost), Sorting and Storing (putting the products in different categories), Asset Recovery (recovering economic and environmental value which includes processes of remanufacturing, refurbishing etc.) and transportation.

There are different types of returns which include manufacturing returns (scrap, defective products), distribution returns (product recalls, packaging returns) and customer returns (warranty claims, end of life products). There are different types of RL mechanism for different products.

Product returns accounts for a large portion of business especially in the retail sector. The products being returned in the retail sector of UK accounts to about $£ 5.75 \mathrm{bn}$ (Bernon and Cullen, 2007) while in USA this amount equals around $\$ 100 \mathrm{bn}$. Considering the huge amount of returns, a sound mechanism is required to handle returned products. Reverse logistics should not be considered optional but it should be considered necessary as very small number of firms have made policies regarding the products that move backward in the supply chain (Autry 2005, p755). Because there are very less standards in Reverse Logistics, it requires greater attention in terms of labor and innovative ways should be devised to handle returns (Richey et al. 2005c). The unavailability of standards can be attributed to the fact that every returned product has different condition.

The food industry is increasing in size day by day. According to European Commission, there are more than 17 million operators and 32 million individuals involve across the food chain (European Communities, 2008). About 2\% of European GDP and 13.5\% of total employment is provided by the food industry (Federalimentare, 2012). The Italian food industry is also very big and consists of 32,300 companies and provides employment to about 405,000 people. Moreover, it exports about 23 billion Euros per year due to the food industry (Federalimentare, 2012). The food sector has a very large impact on the environment in terms of food waste and packaging material. The environmental impact caused by food and drinks sector accounts to about 20\%-30\% of all environmental impacts (Bakas, 2010). Beef products followed by dairy products have the greatest impact on environment (Tukker and Jansen, 2006). The EU food industry is subjected to very strict regulations regarding the environment. As a result of these regulations, companies are compelled to implement reverse logistics to become more sustainable (Nikolaou, Evangelinos and Allan, 2011). Companies are also in the process of making collaborations with food manufacturers to collect and recycle defective or returned packaging material. In a food supply chain, the risks are not tolerable because risk endanger the quality and safety and consequently consumers' health (Marucheck et al., 2011). Due to the global needs, companies have to work to develop such a SC strategy which provides them a competitive advantage in terms of quality, efficiency, sustainability and safety (Christopher and Holweg, 2011).

\footnotetext{
Sukkur IBA Journal of Management and Business - SIJMB | Vol 6 No. 2 July - December 2019 @ Sukkur IBA University 
As the food industry is a retail industry, there exists a large difference between forward and reverse logistics, for example in forward logistics forecasting is very easy whereas in reverse logistics it is very difficult because the number of suppliers (consumers) are great, in forward logistics packaging is uniform whereas in RL it is not, forward logistics cost can be easily calculated, whereas reverse logistics cost are not directly visible, the destinations/ routes are much clear in forward logistics whereas in reverse logistics it is not, the product quality is not same in reverse logistics ( Tibben-Lembke et al., 2002). The returned products come in any type of box or package and there can be a wide variety of returned products (Dutton, 2010).

\subsection{Reverse Logistics in Food Industry}

In context of food industry factors like product expiry, damage, mistake in orders, overstocking and recalls initiate the reverse logistics. The three typical issues in food industry for which reverse logistics is required are food recalls, food wastage and packaging waste. In the food industry it was the grocery retailers who used reverse logistics for handling their returns. This resulted in the development of centralized return centers.

For having a sustainable SC reverse logistics is necessary. RL in food industry mainly deals with the food packaging returns, source conservation, food recalls, recycling, reuse and disposal. It includes collecting packaging material/returned products at collection centers then transferring them to centralized distribution centers and finally recovering the value from it (Accorsi et al., 2011; Das and Chowdhury, 2012). Due to the perishable nature of food items, reverse logistics is very much needed in the food industry. A centralized distribution center is the most commonly used practice to handle return food items (De Koster, De Brito and Van de Vendel, 2002). A centralized distribution center reduces the overall operating costs (Min et al. 2006). This centralized structure enables a better visibility and control of returned products to suppliers and retailers (Terreri, 2010).

The performance of a RL mechanism in a food industry is dependent on several factors such as food specific features, cost, competitive advantage, regulations and information management. According to Coelho, Castro and Gobbo (2011) the impact that reverse logistics can have on environment can be judged by measures such as energy use, $\mathrm{CO} 2$ emissions, water pollution, and urban traffic congestion. The physical characteristics of any food item would decide how the reverse logistics process will take place. Many companies have now acknowledged the importance of RL and have implemented them. For example, nestle has shown a reduction in waste up to $3.1 \%$ and has increased reuse or recovery to $4.2 \%$ (Nestle, 2011).

Defective products are easily returned by customers or retailers but the products that have concluded their life cycle are difficult to obtain from consumers. Same is the case with the packaging material. Once the consumer has used the products, mostly the packaging is thrown away. Companies need to deal with this packaging waste also. According to the Solid waste Management Act No.18 in Indonesia, the manufacturers of anything are required to handle the packaging of the product they are producing and 
the product itself if the packaging or product does not decompose easily in a natural way.

As mentioned earlier, the typical issues for which RL is needed in food companies are the, food recall (food items which need to be brought back due to some fault), Food Waste (recalled food items or items returned by the consumers which are left unattended), packaging waste (packaging returned with returned items or packaging thrown away at consumer's end).

\subsection{Food Wastage}

Food waste is caused when the defected food items are thrown away unattended. Food Waste can be defined as items which have not been sold or consumed at any stage of the supply chain which are considered to be not suitable for eating (Griffin et al., 2009; Kummu et al., 2012; Parfitt et al., 2010; Sonnino and McWilliam, 2011; WRAP, 2013b). In Europe many debates have been seen with the aim of efficiently using the resources and to decrease environmental costs by decreasing food waste disposal (European Commission, 2011; WRAP, 2011). An idea of redistribution of surplus food has been coined to decrease poverty and to reduce waste created by food items. (European Commission, 2012; WRAP, 2014).

Food waste is a very serious problem in the U.S. In the year 2010, it was estimated by the Environmental Protection authority that 34 million tons of food was thrown away which accounts for about $14 \%$ of municipal solid waste in the U.S. A study conducted by Gustavsson and Otterdijk (2011) showed that global food losses and waste are about 1.3 billion tons of food per year that is about $95-115 \mathrm{~kg} /$ year/capita in EU and North America and 6-11 kg/year/capita in Sub-Saharan Africa and South/South east Asia respectively. Household wastes account for approximately $14-26 \%$ of food sales in USA and about $27 \%$ in the UK and the food returns were 1.2-1.8\% of total sales in 2010 (Nestle, 2011; Terreri, 2010). On an average about 520kg per person municipal solid waste is generated in Europe per year and it is estimated that this would increase to $680 \mathrm{~kg}$ per person per year by the year 2020.179 kilograms per capita of food waste was produced by the countries in the EU (O'Connor, 2013). 230 kilograms per year food and drink waste was observed in UK per household and this didn't include packaging waste (WRAP, 2013a). About 5.5 million tons of food waste was observed to be generated from agriculture to households in the Italian Food Supply Chain (Garrone et al., 2013) whereas in the whole Swiss Supply chain the food waste accounts to about 299 Kilograms per capita per year (Beretta et al., 2013).

Food waste is one of the major components of all municipal waste that is created and its disposal in landfills has adverse effects on the environment (EPA, 2009). The food waste that is dumped into landfills goes under Anaerobic decomposing which is the breaking down of organic materials by bacteria without the presence of oxygen which results in the production of methane which is far more powerful in causing global warming as compare to carbon dioxide. The aerobic decomposition occurs in the presence of oxygen which emits carbon dioxide in relatively lesser amounts and does not produce methane. Food waste handling and its delivery to the landfills and 
incinerators is very much expensive and disposing it in landfills can lead to environmental problems and can cause health damages. (Means, Starbuck, Kremer, \& Jett, 2005). Food waste if incinerated can cause problems like combustion efficiency and dioxins (Zurbrugg C, 2002). Due to this reason, a shift from dumping food items in landfill has been observed. This is the reason why Governments are considering to deal with food waste efficiently. The waste strategy 2007 for England considers food waste as a key priority for improving the landfill diversion performance of local authorities (Department of Environment Food and Rural Affairs, 2007).

There can be various reasons for food wastage some of which include excess buying, premature harvesting, inadequate labeling and storage instructions, poor storage facilities and transportation, production errors, trial runs, packaging defects, and wrong weights and sizes (Fotopoulos, Vlachos, and Maglaras, 2010; Gustavsson and Otterdijk, 2011). Wrong labeling has been a major cause of food wastage. This has generated about three million tons of food and drink wastage (Karolefski, 2007). Whatever the reason may be, there is a need of a sound reverse logistics system to deal with it. About $96 \%$ of the food wastage occurs because of cooking too much food and food which is not used before the date of expiry (WRAP, 2009). Mostly people think that food items are biodegradable and cannot be damaging for the environment. Mostly food losses and waste in low income countries occur during the early and middle stages of food supply chain. The reason being the inadequacy of managerial and technical limitations while in high income countries food losses occur at the later stages of the supply chain reason being limitations and regulations e.g., quality standards and consumer behaviors e.g. excessive buying, inability to understand best before dates and left overs (Parfitt, Barthel and Macnaughton 2010).

\subsection{Food Waste Recycling and Disposition}

The food waste that is created should be catered efficiently. Most of the time this food waste is dumped into landfills. This causes leaching in the soil which pollutes the water under the soil. Moreover, this type of food waste, when dumped in landfills, creates methane by the action of bacteria which is a greenhouse gas and adversely affects the ozone layer. This type of disposal in landfills creates another problem of limited space. Other than this, food waste is a valuable resource that can be used to create something useful such as Biogas and feeds for animals. This can result in additional benefits for the company both in terms of finance and environment friendly image. For recycling of food waste, one needs to have a mechanism by which food waste can be gathered and properly recycle or if needed properly disposed off..

Food recycling is being implemented in many countries. IKEA along with Cyrenians Organics Waste Recycling (CORE) presented a different approach to food waste recycling in its Edinburgh Store in 2009. IKEA successfully recycled food waste into many useful products. Before 2009 all food waste was sent to landfills. The Food waste recycling was introduced in two phases. Beginning in October 2009, the first phase included segregation of food waste that was created at the food preparation site. This waste was then used to make Fertilizers and energy at a local anaerobic digestion plant.

Sukkur IBA Journal of Management and Business - SIJMB | Vol 6 No. 2 July - December 2019 ๑ Sukkur IBA University 
The second phase which was started in June 2011 aimed at recycling food waste that was created by the customers in the cafeteria. This included placing three different bins at the cafeteria for food waste, general waste and recycling. Implementing such strategies enabled the store to decrease its greenhouse emissions which resulted in carbon dioxide savings of 15.2 tons and 6.8 tons of methane each month with a monetary benefit of 1200 Euro (Zero Waste Scotland). In Japan, the Law for the promotion of Effective Utilization of Resources has enabled the country to excel in recycling, waste management and health protection (OECD 2010; Koizumi 2008; JSWME 2007; MoE 2013a). Especially food waste recycling in Japan is considered to be very important as it makes up one fourth of municipal solid waste and has large effects on the environment. (Melikoglu, Lin, and Webb 2013; OECD 2010).

One of the major strategies to deal with food waste is to turn it into Compost. This has been widely utilized to handle food waste in many countries. Compost is the most suitable process for handling food waste. This process takes place by making a heap of wet organic matter and waiting for them to break down or decompose by the action of bacteria and fungi in the presence of oxygen. This method is far better than throwing away food items in landfills. When the food waste is dumped into the landfills, it gets pressed down and liquefies and gets intermingled with toxics and seeps into the ground polluting the water in the ground (Crawford, 2003). This compost is used as a fertilizer and results in less emission of greenhouse gases which are produced during the manufacturing of synthetic fertilizers. Overuse of Synthetics Fertilizers is the largest reason of Nitrogen Flux down the Mississippi and Atchafalaya rivers to the dead zone in Gulf of Mexico. (Gruby \& Crowder, 2009). Furthermore, the nutrients from the synthetic fertilizers are taken in a very small amount by the plant, while the excess of nutrients go to rivers, lakes and coastal area and causes pollution (Dybas, 2005). The nutrients from Compost are released slowly, which decreases the loss of nutrients (Sulivan, 2004). Taking care of food waste by compositing not only reduces the need of synthetic fertilizers but also prevents plant diseases and pests increasing the yield (Larkin, Tavantzis, Bernard, Alyokhin, Erich, \& Gross 2008). This type of food waste handling results in the increase in the soil quality, soil water retention and reduces the need of extra efforts (United States Composting Council, 2008).

Many other alternatives have been developed to handle food waste effectively which are beneficial economically and environmentally. Food Recycling Law was enforced in Japan in 2001 with an aim of reducing the food waste and reutilization of food resources. Alfo Ltd. in Japan uses cooking oil to deep fry food waste, sterilize it and dry the final product to produce raw materials for making feed. In the same way Bio Energy uses food waste to generate $24000 \mathrm{kWh}$ electric energy. The revision of the law in Japan encouraged the conversion of food waste into feed or fertilizer and coined the term "heat recovery" (MAFF 2008a; Tanimura 2008). This revision also demanded to report the amount of food waste generated and reusing it to the Ministry of Agriculture, Forestry and Fisheries (MAFF). The waste producers were asked to buy food which is grown using food waste derived products. This resulted in the recycling of resources completely. This resulted in lower greenhouse gas emissions and economic efficiencies 
as compared to previous waste disposal techniques (MoE 2013c; MAFF 2013b; Takata et al. 2012). Another example is of supermarket chain Uny Co. Ltd. Which provides its food waste to a recycling company named Sanko Ltd. Sanko produces fertilizers that are bought by agricultural/ forestry/fishery dealer who uses these fertilizers to produce vegetables, fruits, rice etc. Similarly, at Mister Donuts left over donuts are used in making feed for livestock.

Similarly, in Korea, food waste is being converted to many useful products. According to the Korean Government Food wastes were disposed off properly by recycling them into mainly animal feeds and compost (Ministry Of Environment Korea, 2008). The Government of Korea has set up Dry feed facilities and compositing facilities. In Korea three different ways of Food waste disposal were observed. The goal of each was to reduce the waste produced and environment friendly disposal. The first method was Anaerobic Digestion in which Biogas was produced by the process of hydrolysis, acidification and methane fermentation which could be used to produce electricity. The second method was Co-digestion with sludge in a sewage treatment plant to produce Biogas. The third process is incineration in a dryer. This process involved removing the moisture content from food waste and burning it at a temperature of 850 to 1100 degree centigrade along with municipal solid waste to produce steam which could be used to run a steam turbine and as a result produce electricity.

Hong Kong is also facing the problem of food waste. Hong Kong has a limited area for disposing of municipal solid waste. About 9000 tons of solid waste was dumped every day in 2012. It has been forecasted that the three main landfill sites would reach their maximum limit by the year 2020 (HKEPD 2013). Out of this 9000 tons of waste produced about 3600 tons comprise of food waste and out of this 3600, about 2500 tones is produced by households and about 1100 tons from food concerning commercial and industrial avenues. Food waste recycling is not so much popular in Hong Kong. About $0.6 \%$ of the food waste created in 2016 was recycled (HKEPD 2014b). To cater such an enormous problem of food waste many techniques have been adopted by Hong Kong Special Administration Region Government. These techniques mainly involve prevention of food waste at its source, redistributability of food for human consumption, recycle the food waste and disposal of MSW (HKEB 2013).

Adding food waste into sewage sludge increase the Bio gas output which provides more energy for electricity production (Sosnowski et al. 2008). This is due to the fact that food waste can produce methane three times more than sewage sludge (USEPA 2013). Moreover, this Biogas can be used as a fuel for vehicles as biogas has high methane content (about $98 \%$ by volume) (Patterson et al. 2011). From an environmental perspective, the use of Biofuels can reduce the need of fossil fuels and consequently would produce lesser GHG. The greenhouse gas emissions can be reduced by 75 to 200 percent using Biogas fuels as compared to Fossil Fuels Papacz (2011). Using Biogas as fuel for generating heat and electricity has economic advantages as compared to fossil fuels (Murphya et al., 2004). Biogas generated from $1 \mathrm{~kg}$ of food waste is equal to about 0.13Liters of petrol (Hafeez, 2013). This bio gas can drive a car with engine size of 2501-3500 $\mathrm{cm} 3$ providing an average consumption of 14 liter/100km to drive 
$0.93 \mathrm{~km} / \mathrm{kg}$ treated food waste (EMSD 2013). Moreover, using biogas fuel in 12000 cars would result in the reduction of carbon dioxide to about 96000 tonnes per year (Rydberg et al. 2010). Sweden has employed about 32 Biogas upgrading plants. (Patterson et al. 2011). In Linkoping, a biogas plant produces about 4.7 million $\mathrm{m} 3$ of upgraded biogas fuel which is being utilized in 64 buses and in some light and heavy vehicles (IEA Bioenergy 2014). It has been observed that a bus running on biogas fuel reduces carbon dioxide emissions by 90tonnes/year and nitrogen dioxide emissions by 1.2 tonnes/year (Francis and Bell 2008). The organic recovery center in France, produces biogas for 100 urban buses and 10 waste collection trucks (BCEP 2014). Standards have been made for utilizing biogas as a vehicle fuel in countries like Sweden, Switzerland, Germany and France (Patterson et al. 2011).

As it can be seen that how much food waste can adversely affect the environment and by recycling this waste how a company can get financial benefits, it is necessary that there should be mechanism developed which collects these food wastes efficiently and recycle it as much as possible. This system is named as Reverse Logistics as it provides strategies to collect waste and salvage value from it.

\subsection{Packaging Waste}

Another source of waste is the packaging material of food items. Packaging refers to the technology and material for enclosing or protecting products for distribution, storage, sale, and use (Soroka, 2002). The most common type of packaging material used is paper which accounts for about $34 \%$, then there is rigid plastic which is $27 \%$ of the total, followed by metals which is about $15 \%$ after that there is glass accounting for $11 \%$, flexible plastic $10 \%$ and other materials about 3\% (Rexam, 2011). About $50 \%$ of Plastics are used in disposable items such as packaging, agricultural films and consumer items, about $20-25 \%$ are used in products such as pipes, cables and structural materials while the rest is used in durable consumer items such as in electronic goods, furniture and vehicles etc. The EPA calculated that about $31 \%$ of municipal solid waste was due to packaging material which includes glass, metal, paper in 2005 (EPA, 2006a). Barnes et al. (2009) says that the packaging, electrical equipment and plastics from end of life vehicles contribute majorly towards both household and industrial waste. The most common use of taking care of this waste is landfills but landfills have limited capacity to cater these wastes (Defra et al. 2006). the plastic waste accounts for about $10 \%$ by weight of the municipal waste (Barnes et al. 2009). About $47 \%$ of the $520 \mathrm{~kg}$ per capita household waste created in Europe in 2004 was catered by landfills (EFA, 2008). It could be very much harmful for the human as well as animals. It has been found that in more than 260 species which include invertebrates, turtles, fish, seabirds and mammals ingested plastic debris which have caused many problems such as ulcers, decreased reproduction and death (Laist 1997; Derraik 2002;Gregory 2009). Plastics have a long life. Due to this very reason if they are disposed to landfills, it is merely keeping the problem for the future (Barnes et al. 2009; Hopewell et al. 2009). Another major issue with landfill is that none of the material resources used to produce plastic are recovered which means that the material flow is linear instead of cyclic (Oehlmann et al. 2009; 
Teuten et al. 2009). In countries like Japan, the excavation for landfilling is really expensive because of the hard surface of the underlying volcanic bedrock while in Netherlands it is expensive due to the penetrable nature of the land due to sea. The plastic has caused much pollution as they are not easily decomposed. The environmental implications of reclamation, reuse and recycling to save landfill space, energy, and costs are vital for organizations (Sarkis et al., 2010). Packaging should be made as such that it should be easily disposed off if not recyclable because most of the time packaging is one way and has very great effects on environment (Andersson and Ohlsson 1999; Lewis 2005; De Monte et al.2005). With the increasing usage of packaging material there has been an increase in the problem of waste disposal which has resulted in landfills near urban populations (Reynolds 1993, 1; Twede and Goddart 1998, 9-12; Gidarakos et al. 2005). Every year in the United States, the paper, aluminum, glass, plastics and other recyclable material is thrown away. Recycling this material would result in an amount of approximately $\$ 11.4$ billion. Single-use food and beverage packaging contributes to about 269000 tons of plastic pollution in world's oceans (EPA, 2006a). Since the Plastics are made of durable polymers, large quantities of discarded plastics accumulate as debris in landfills and natural habitat. Recycling of plastics results in reduced usage of oil, lower carbon emissions and eventually lower quantity of wastes.

Another way of dealing with plastic waste is to burn them. Incineration reduces the need of landfills but hazardous materials can also be released into the atmosphere. PVC and other halogenated plastics, when incinerated, releases dioxins and other polychlorinated biphenyls into the environment (Gilpin et al 2003).

Recycling is the most effective way of reducing this environmental impact and resource depletion. Many countries in the world have identified the importance of reducing the impact of their operations on the environment and have started to apply optimization techniques (Beamon, 1999; Farahai et al., 2010). Carter and Easton (2011) said that the development of models and decision support systems which directly interact with the environment, social and economic performance is necessary. According to the European directive 94/62/CE, packaging manufacturers and manufacturers who use packaging are responsible for recovery of a percentage of what they place in the market. Considering all these problems, some companies have taken initiatives towards the reduction of packaging waste. Starbucks, for example, in collaboration with paper recyclers have taken a step-in recycling greasy and food stained paper. It has initiated the preferred supplier program which rewards suppliers for both environmentally and socially responsible practice (Schrage, 2004). On the same lines McDonald's focuses on its sourcing practices while keeping the environment in consideration by going for factors such as water and energy conservation, air pollution, waste and recycling, habitat preservation and use of chemicals (McDonald's, 2004). Kellogg Co. in 2000 developed a closed loop supply chain. This closed loop supply chain combines traditional forward supply chain activities with return management. The loop closes with accountability from all functional areas which include customer service, distribution centers, logistics, marketing, packaging, remarketing and returns 
management, research, retail sales, quality and packaging suppliers. This plastic waste should not be left unattended. When a plastic degrades under the influence of weather, it first decomposes into small pieces of plastic debris, but it is not necessary that the polymer may completely degrade. Due to this, large quantities of plastics are piling up in landfills causing waste management issues and environmental damage. (Barnes et al 2009; Gregory 2009; Oehlmann et al. 2009; Ryan et al. 2009; Teuten et al. 2009; Thompson et al. 2009).

Since most of the food items are sold in plastic packaging, the packaging waste from food items contribute a lot towards the waste created. This packaging waste needs to monitored and managed in the most suitable way. The best way to avoid packaging waste is to recycle or reuse it. It not only has positive effects on the environment but also can provide many avenues for cost efficiency. Using recycled plastic materials have proved to be more profitable due to continuously rising prices of oil (WRAP, 2007). This waste plastic has many useful benefits. This can be again used in the packaging of new food items. These can be used in making other plastic items or can be used to produce Electricity by direct combustion or by changing it into fuel resulting in the reduction in usage of landfills (Garforth et al 2004). A life cycle assessment specially for PET bottles indicated that the use of $100 \%$ recycled PET instead of $100 \%$ Virgin PET would result in a reduction of carbon dioxide from 446 to $327 \mathrm{~g}$ per bottle which would ultimately result in the emission reduction by $27 \%$ (WRAP, 2008e). The recycling of post-consumer plastic have less environmental effects than producing virgin plastic (Wong, 2010).

Companies have to deal with the packaging that comes with the returned products but also with the packaging waste that is created at the consumer's end. Due to increased Environmental considerations, it is not only necessary for food producers to deal with packaging of returned items but dealing with packaging waste created by their products at the consumers' place is also considered to be a part of his duties. In the year 2014/15 in UK 492,623 tons of plastic packaging waste was collected from the households (RECOUP Household Survey 2015). The plastic waste generated by consumers in 2007 in the European Union was 24.6 million tons. (Plastics Europe, 2008b).

The packaging material which comes back with the returned products is easily collected but the plastic waste that is created at the consumers' end is very much difficult to gather. Refilling schemes and take back schemes have been introduced in several European Countries which include both PET and Glass bottles (Institute for Local Self-Reliance, 2002). Such schemes are only fruitful, when the consumers are highly committed towards the environment or some incentives are given to them. Another method is to have a deposit refund scheme in which consumers are charged at the time of purchase and are refunded when they return the empty packaging or bottle.

\subsection{Food Recalls}

Now the business aspect for which reverse logistics is required in food industry is the Food Recall. A food recall is majorly initiated because of some defect in the food items. A food recall is carried by a manufacturer or distributor to protect the people from items

Sukkur IBA Journal of Management and Business - SIJMB | Vol 6 No. 2 July - December 2019 @ Sukkur IBA University 
which could lead to health problems or even worse, death. Product recalls basically portrays the quality failures the consequence of which is a harm event (Siomkos \& Kurzbard, 1994).

During the first quarter of 2012, about 142 recalls were made by more than 130 companies (about 9 companies having multiple recalls) in the U.S. alone (FDA, 2012). According to the Consumer product Safety Commission (2012) the damages caused by product harm events are quite great irrespective of that whether the event has occurred due to faulty consumer product, food borne illnesses. This account to about $\$ 900$ billion annually in terms of unsafe consumer products, healthcare and property damages. Healthcare costs account to about $\$ 77.7$ billion due to food caused pathogenic illness (Scharff, 2012). Roberts (2007) says that one out of six gets affected by food borne illness and this causes an amount of $\$ 1.4$ trillion annually in terms of heath care costs and productivity losses. Product recalls have both indirect and direct costs to the company. Market share, shareholder value and reputational impacts to the firm all are measures of indirect costs whereas reverse logistics, warranty, replacement, and repair costs along with product liability are the measures of direct costs (Jarrell \& Peltzman, 1985; Rupp, 2003). Despite such huge costs' companies are rarely considering a proper mechanism for product recalls. Companies do not pay much attention towards the reverse processes in terms of their effectiveness and efficiency as compared to the attention they give towards forward logistics (Reverse Logistics: Returns, Refunds and Recalls, 2009).

In case of food recalls defective items should be taken off the shelves immediately and collected. After proper collection, they can be dealt with in the most suitable way. This collection and dealing with defective products is only possible when a company has a sound system for collecting and handling these items i.e. Reverse Logistics.

To have an efficient recall mechanism, it is necessary that all stakeholders within the supply chain have a close cooperation and coordination. Some determinants of efficient reverse logistics process are good inventory management, good relationships among the stake holders of supply chain and good management information systems. The supply chain recall detection competence means that all stakeholders within the supply chain work collectively on operational monitoring, integration and coordination. This includes all the monitoring systems, all communication channels, feedback mechanisms and integration strategies which allow the supply chain to identify problems at first hand and solve them faster (Cohen \& Levinthal, 1990; Tu, Vonderembse, Ragu- Nathan \& Sharkey, 2006). Having a reverse logistics system identifies where the problem exists, thus helps in reducing the number of returns.

\subsection{Reverse Logistics in developing country like Pakistan}

In spite of the importance of RL, there has been less work done specially in Pakistani industry. Less work has been done on how to deal with products that are returned or have completed their life. A neglected area in Reverse Logistics is how to handle end of life products, especially how to recycle them or properly dispose them off (Binget al., 2014; Ritchieet al., 2000; Xie and Breen, 2014) (Mishra et al., 2012). Wright et al.

\footnotetext{
Sukkur IBA Journal of Management and Business - SIJMB | Vol 6 No. 2 July - December 2019 @ Sukkur IBA University 
(2011, p. 10) has said that the development of recycling channels has received less attention. In spite of the importance of reverse logistics companies do not employ it. There is a dearth of literature on RL in spite of the importance of the subject (Dowlatshahi, 2000). Less work has been done on the strategic aspects of Reverse Logistics (Rubio et al. 2008). Reverse and recycling supply chains have been neglected in the supply chain area (Wong 2010). Less literature is available on the application of Reverse Logistics in Food Companies. The literature that is available is mostly from the manufacturing side. Iron and steel industry, commercial aviation or medical products sectors to name a few (Dowlatshahi, 2000). No proper work has been done on the problems that companies face while employing reverse logistics. No proper research has been done on the current practices being employed in handling returns.

\subsection{Barriers to Reverse Logistics}

The literature has mentioned several reasons due to which companies do not establish a Reverse Logistics system.

For the success of any Logistics operations, top management support is essential (Daugherty et al., 2001, 2002; Guide and Van Wassenhove, 2001; Richey et al., 2005b). This means that the management must commit resources for personnel allocation, employee training and for managing the relationships between consumers and partners in the supply chain. Resource commitment has found to be positively related to RL capability (Jack et al., 2010).

For a successful RL system, it is necessary that all the stakeholders are made aware of the returned products at each channel of reverse process as it results to the formalization of processes. Timely delivery of accurate and clear information is necessary to achieve operational efficiency and customer satisfaction (Genchev et al., 2011).

Different studies have pointed out different difficulties. The relative unimportance of Reverse Logistics is the major barrier in the implementation of RL system (Rogers and Tibben-Lembke 1999). The companies may not be attentive towards efficiently handling returns. The absence of internal policies because the employees are unaware of the processes is another barrier which hinders the development of RL process (MARTINS; SILVA, 2006). Cultural barriers also contribute to the hindrance in developing of RL system, because the concepts of sustainability, reducing environmental burden, proper waste disposal though being popular are hardly practiced by both consumers and companies (LEITE, 2009). Many companies do not reuse the returned parts because they don't have any kind of knowledge about how to reuse those (Wahab et al. 2010). It has been found that the hindrances in the implementation of RL in European countries include lack of senior management attention, lack of extended producer responsibility concept, not recognizing RL as a thing which could give an added advantage to company relative to the competitors, not having proper management systems, no collaboration between stakeholders, not good enough planning and forecasting of return products and not having the notion about adverse effects on the environment because of not having a RL process.(PricewaterhouseCoopers, 2008).

Sukkur IBA Journal of Management and Business - SIJMB | Vol 6 No. 2 July - December 2019 @ Sukkur IBA University 
Cost is also one factor. Garrone et al. (2014) show that food recovery efforts are often limited by financial and logistical constraints that make it difficult to supply recovered food to potential recipients. Another thing to add here is the high cost of recycling systems as compared to the value recovered from the returned products which creates a problem of low profitability (Brito; Seara 2010). Companies hesitate in implementing Reverse Logistics because there are no indicators available that measure the cost benefits of having a reverse Logistics system. This lack of indicators results from the unavailability of knowledge or no awareness about the cost of operations (Shibao et al., 2010).

Absence of authentic knowledge on how companies should handle and deal with returns is scarce and the relative unimportance causes the company to resist in developing RL process. As there is less knowledge available on recycling and remanufacturing as a consequence very minute amount of materials are reprocessed therefore RL is not considered a great value-added activity (Kinobe et al., 2012). According to Chan and Chan (2008) the reason that companies do not indulge in Reverse Logistics is the insignificance that companies gives to RL. This is due to the reason that companies do not focus on the positive effects that a RL system can have. As mentioned earlier, not having a clear return policy is also a major barrier, so by making a clear return policy, the control over returns can be increased and abuse from customers in terms of product return can be reduced (Autry, 2005; Genchev et al., 2011; Richey et al., 2005b). As RL is a part of green SCM, the barriers in the development of GSCM involves the lack of awareness (which includes lack of top management support), technological limitations, the scarcity of environmental information and trainings (Nikbakhsh, 2009).

The unavailability of new methods and skilled people is also considered to be the one of the hindrances. It has been observed that companies use labor oriented, manual, inefficient reverse logistics processes. (Thrikutam \& Kumar, 2004). Many companies do not have efficient Reverse Logistics management softwares (Rupnow, 2011). Poorly defined return processes make the location, identity and conditions of returned items difficult to be known which is attributed to Poor Knowledge about RL (Thrikutam \& Kumar, 2004). The scarcity or unavailability of executives who can focus on RL and can take the responsibility of reverse operations is one of the major hindrances in the successful implementation of RL process (Tompkins, 2010) (Rukavina in Walsh, 2007; Starkowsky in Andel, 2004). The unavailability of specialized information systems that handle could handle the peculiarities such as quantity and frequency of return is another obstacle (GARCIA, 2006; YANG et al, 2008).The absence of skilled professionals in the area of Reverse Logistics is also a major problem (AITA; RUPPENTHAL, 2008).The absence of an effective information system is also a major hindrance in implementation of RL (Zheng et al., 2005).

\section{Research Methodology}

The research has been conducted on two food companies operating in Lahore. Both companies are dealing in different food items such as bakery items e.g. Biscuits, cakes, sandwiches etc. and liquid items such as milk and soft drinks. These two companies

Sukkur IBA Journal of Management and Business - SIJMB | Vol 6 No. 2 July - December 2019 ๑ Sukkur IBA University 
were chosen because they have been working in the food sector for a long time and deal in same kind of food items i.e., confectionary. Furthermore, they hold a major share among companies that deal in food items in Lahore. Both companies are competitors with almost same type of items which can provide a good comparison between the Reverse Logistics practices of both companies.

The study sues an interpretivism paradigm in this study. Furthermore, the research strategy employed in this study is Qualitative. As this study explores the reason for absence of Reverse Logistics activities in Food industry, qualitative approach is considered to be the best for this purpose. Data is collected by observation and interaction with the participants. The techniques used are participant observation, in depth interviews, semi structured interviews and focus groups who were closely involved in the Return Process which included procurement manager, plant manager, supply chain manager, shipping manager, quality assurance manager. An interview guide was prepared from the literature to serve as a guideline to extract information from the participants

In the current study, inductive approach is being used. This study has also used case study as a means of gathering data. The target population for this research consists of Local Food companies which are operating in Pakistan. The non-probabilistic sampling technique used for this study is Purposive sampling.

The research uses cross- case synthesis. Moreover, the data is analyzed using NVIVO. It helped to create themes regarding the use of RL activities in Local Food Companies and the difficulties that companies face when implementing a RL process. The findings from both companies have been compared with the literature in the form of tables which helped to point out the similarities and differences between the previous studies and current study. The results of NVIVO also showed the differences in the RL practices of both companies and the barriers perceived by executives of both companies in the implementation of RL. Lastly, validity of this research is carried by triangulation and validity of this research is proved from the fact that the responses taken from the participants of each case company conform to each other. These interviews were taken at different times separately. Moreover, the personal observations could also serve as a method of providing the validity. The processes were in accordance with the findings from the interview. Furthermore, the findings from the semi structured interviews were also consistent with the literature on Reverse Logistics. The findings had internal consistency as three different people had the same views about the key research questions.

\subsection{Conceptual Framework}

A review of literature has established the importance of reverse logistics in food industry. It is necessary for the food companies to engage themselves in RL process to gain the described benefits in terms of recycled products as well as to fulfill their responsibility towards the environment. The proposed framework below represents the way of exploring the current practices regarding RL in food Companies. It will identify the barriers that companies face while developing a RL mechanism. The proposed 
framework starts by finding out that how much the companies are aware about Reverse Logistics which includes asking them about their understanding of Reverse Logistics. The next step is to ask them the kinds of returned items. The third step would be identifying the actors who are involved in handling the returns. The next step is asking them how they handle returns and how do they cope up with the waste food material and packaging waste currently. Next step would be asking them what the barriers in developing a RL mechanism are.

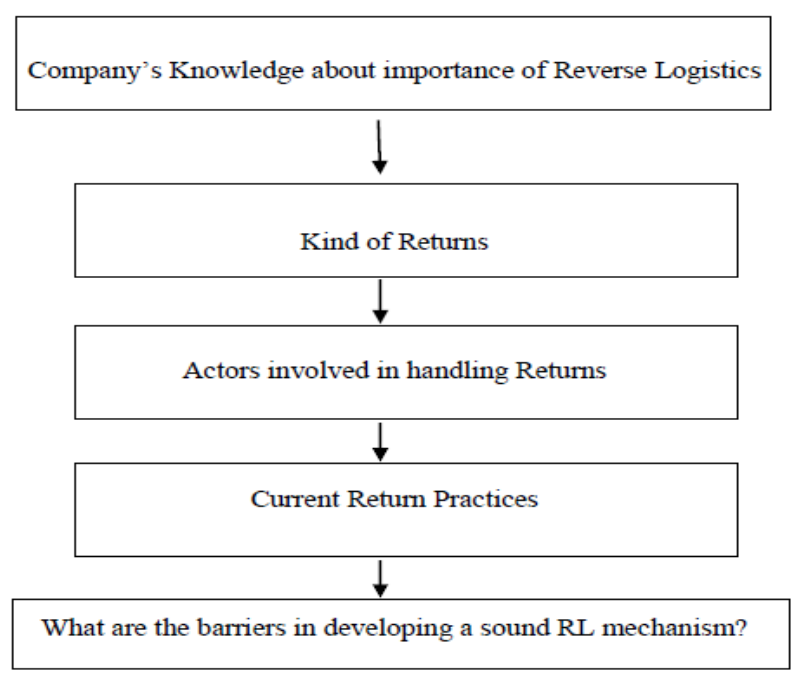

Proposed Framework for exploring the adoption of reverse Logistics in food industry

\section{Analysis and findings}

The Executives of Company $\mathrm{ABC}$ were asked that what they know about the term Reverse Logistics. Two out of three executives were aware of the term and gave their perception about Reverse Logistics. One of them said that it is the process of bringing back the product to the premises of the producer due to some defect or problem. The other said that it is the management of Returns. The third executive didn't know about the term but he knew about the reversal process of things. He knew how the products were returned and what happens with them.

The Executives of Company XYZ didn't know about the term "Reverse Logistics". They knew what the return process was but they were not familiar with the term. They were performing the Returns process but were unaware that this is a major topic which needs to be focused on.

The Reverse Channel of Company $\mathrm{ABC}$ uses the same resources as the Forward Channel. The things which need to be returned are kept isolated in the outlets. The 
Supply trucks which deliver fresh products to the outlets, take these products back on their way back to the factory.

Once the products have reached the factory, they are kept in a separate place and decisions are taken about the fate of these products.

Company XYZ has also the same reverse channel as of Company ABC. The product returns are placed separately in the shops. The supply truck takes back the returned items to the factory.

\subsection{Reverse Logistics process}

According to the definition of Reverse Logistics, the true purpose of Reverse Logistics is to efficiently reuse or recycle or use the returned products in the manufacturing of other products or properly disposing off the products. Due to increased awareness about reverse logistics, companies in the foreign countries acknowledge their responsibility of dealing with returns in an environment friendly way. There have been practices in which companies collect the waste created by their products and efficiently handle them either by recycling them or disposing them. Companies like Starbucks and McDonalds have initiated several projects of handling wastes. But there are lot of hindrances faced by the company in developing such a process that adequately handles the returns. Many companies which have thought of having a system of Reverse Logistics face a number of difficulties.

According to Stock and Mulki (2009) even If a company has some kind of executive for reverse logistics, it is not his main duty to focus on Reverse operations or it may be performing some other works other than reverse logistics. Sometimes the companies consider that returns are failures so management does not want to focus their attention towards RL (Rogers \& Tibben-Lemke, 2001). For having a successful Reverse Logistics process, there is a need of departmental collaboration. But due to the lack of departmental coordination and effective communication, the benefits of RL cannot be gained (Lang in Hoffman, 2006; Rukavina in Walsh, 2007). Until and unless there is proper exchange of information among the departments and until all departments do not understand the importance and ultimate objectives of RL, Reverse Logistics cannot be utilized to gain advantages. Senior management should know about their current RL practices and should consider it in the strategic planning of the organization (Tompkins, 2010).

The executives of the companies under consideration were asked the reasons for not having an efficient RL system in our industries especially food industry. The executives gave 4 major reasons which according to them are the causes that do not allow a company to have a RL system. The 4 major reasons identified are Lack of finance, Lack of knowledge and expertise, Lack of governmental regulations and lack of management interest.

As for company $\mathrm{ABC}$, when the executives were asked that according to them why companies do not involve in implementing a Reverse Logistics process. The major reason given by all three executives was the lack of knowledge or expertise. According to them, companies here do not have the slightest notion about how reverse logistics 
can be beneficial for their companies. They do not know how to reuse or recycle the items and do not know how to properly dispose them off. The absence of experts is also included in this aspect. According to them there is a dearth of professional people who have the expertise in handling returns. There are no experts who can devise ways to deal with the returned products whether it be recycling/ reusing the returned items or disposing them off. According to them the biggest reason for not having a systematic reverse process is the scarcity of knowledge and personnel who have expertise in return. Another reason highlighted by the two people out of three is the Lack of finance. This is also in connection with the lack of expertise. When companies do not have the necessary resources to hire people who have the expertise in handling returns, this could lead to the absence of RL system. Finance is also required for the proper training of workforce who will actually handle the returns. So when companies do not have the money to invest in the development of an RL system, one could not efficiently handle returns.

Another issue indicated was the lack of management attention. According to them, the absence of a reverse Logistics system is due to negligence exercised by the management. Management does not consider returns as a beneficial thing. They do not want to go for the processes of recycling/reusing or properly disposing off the returned items and don't want any hassle. They do not consider the detrimental effects these returns could have if left unattended or benefits that can be provided by such a system. This negligence could also be linked to the lack of knowledge about Reverse Logistics. When companies do not have knowledge about any of the benefits of Reverse Logistics or the implications of not having one, they won't be inclined towards having a sound system of reusing/recycling or disposing off items properly and waste their energies unnecessarily.

Talking about company XYZ, the executives had different opinions about the hindrances in developing a RL system. Two persons out of three said that one of the barriers is lack of knowledge or expertise about Reverse Logistics. Mostly companies and people don't know about the benefits that companies could have by developing a proper system for recycle/reuse or by properly disposing off the returned products. They do not know how damaging these returned products could be for the environment as well as for the company itself. Two persons had the view that lack of regulations is the major barrier. When companies are not enforced to handle their returned items and take responsibility of the waste created by their products, companies will not take this Reverse Logistics System seriously. The absence of laws is one of the major reasons that companies do not take any step in dealing efficiently with returns. One person said that the lack of finance or resources is also a barrier. When a company does not have any resources for dealing with returns, a system cannot be developed. Everything requires some investment in terms of technical personnel, training of workers, and research about how to deal with different types of returns. Another person pointed out the inattention of management towards this aspect of regaining value and taking responsibility of dealing with returns, another reason for not having a RL process.

The NVIVO results of this query are as follows:

Sukkur IBA Journal of Management and Business - SIJMB | Vol 6 No. 2 July - December 2019 @ Sukkur IBA University 
Table 1:Matrix Coding Query for Barriers to Reverse Logistics

\begin{tabular}{|c|c|c|c|c|c|c|}
\hline & $\begin{array}{c}\text { Intervie } \\
\mathrm{w} 1 \\
\mathrm{ABC}\end{array}$ & $\begin{array}{c}\text { Intervie } \\
\mathrm{w} 2 \\
\mathrm{ABC}\end{array}$ & $\begin{array}{c}\text { Intervie } \\
\mathrm{w} 3 \\
\mathrm{ABC}\end{array}$ & $\begin{array}{c}\text { Intervie } \\
\mathrm{w} 4 \\
\mathrm{XYZ}\end{array}$ & $\begin{array}{c}\text { Intervie } \\
\mathrm{w} 5 \\
\mathrm{XYZ}\end{array}$ & $\begin{array}{c}\text { Intervie } \\
\mathrm{w} 6 \\
\mathrm{XYZ}\end{array}$ \\
\hline $\begin{array}{c}\text { Lack of } \\
\text { Finance }\end{array}$ & 0 & 1 & 1 & 1 & 0 & 0 \\
\hline $\begin{array}{c}\text { Lack of } \\
\text { knowledge } \\
\text { or } \\
\text { expertise }\end{array}$ & 1 & 1 & 1 & 1 & 1 & 1 \\
\hline $\begin{array}{c}\text { Lack of } \\
\text { regulations }\end{array}$ & 0 & 0 & 0 & 0 & 1 & 1 \\
\hline $\begin{array}{c}\text { Lack of } \\
\text { manageme } \\
\text { nt interests }\end{array}$ & 1 & 1 & 1 & 0 & 0 & 1 \\
\hline
\end{tabular}

This is a result of a Matrix Coding query. The 0 and 1 here represents the absence and presence of a particular barrier in a particular interview.

It can be seen that all six interviews have " 1 " in the "Lack of knowledge" Row. This shows that six people had responses about Lack of Knowledge or Expertise as the major barrier in their responses. Thus, considering this to be the major barrier.

"Lack of finance" has three " 1 " in row. This shows that out of six people, three people had responses related to lack of finance and considered this to be another barrier.

Three out of six people had the view that "Lack of Management" interest is also the barrier.

Only two people said that "Lack of Regulations" is a barrier in development of a RL system.

Based on these responses, it can be said that the major barrier which restricts that development of RL system is the Lack of knowledge and expertise. After that 'Lack of Finance" and "Lack of Management Interest" is another barrier. The least given reason is the "Lack of Regulations".

This model shows the different sources coded at the nodes of "Lack of finance" "Lack of Regulations" "Lack of expertise or knowledge" and "Lack of Management interest". Since each source represents one interview, this model shows that who considered what to be the barrier. It can be seen that arrows from "Lack of regulations" is directing towards interview 5 and 6, which indicates that the interviewees 5 and 6 had responses towards Lack of Regulations as a barrier and hence considered Lack of regulations to be one of the barriers. "Lack of Management Interest" is indicating towards interview 2, 3 and 6, so these people considered this aspect to be one the barriers. "Lack of Management" is pointing towards interview 1,2,3,4 and 5 so this shows that these people considered this to be the reason for not having a RL system. The next section 
represents the comparison of Barriers to RL between the previous studies and the case companies under study.

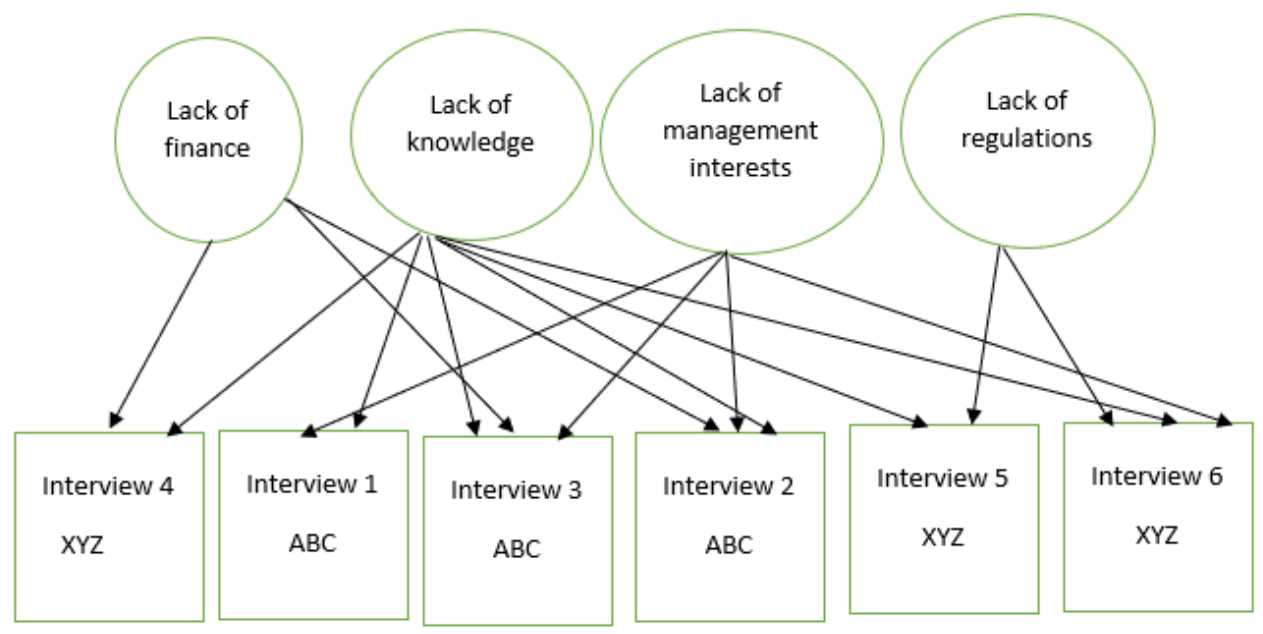

Figure 1: Source coding for barriers to reverse logistics

\subsubsection{Governmental Regulations}

Since laws regulate a society, so the presence of laws is really necessary for the smooth flow of a system. One of the major factors we see about Reverse Logistics in the foreign countries is the presence of regulations that enforce companies to take responsibility of their actions and to own the responsibility of the waste that their products create. According to Martel; Vieira (2010) the laws for preserving the environment have become stricter due to which companies are considering to adopt Reverse Logistics. These laws also ensure that the activities of recycle/reuse should be done in a way so that less waste is created by their products and if a product cannot be recycled, the company should responsibly discard the waste product. An example of such a law is Waste Electrical and Electronic Equipment. Legislations such as Plastic beg Levy in Ireland have highlighted the importance of recycling or re use of plastic bags (Department of Environment Heritage and Local Government Ireland 2007). Such regulations have made it necessary that the manufacturers take the responsibility of collecting, treating and recycling and/or safe disposal of their products and the materials used in their manufacturing after their life ends (Lai and Wong, 2012; Zhang et al, 2011). In 2008, the EU packaging directive necessitated the recycling of50 \% metal, $22.5 \%$ plastics and $60 \%$ of glass beverage packaging. The EU Directive 94/62/EC is formulated to reduce the negative impacts on the environment by reducing plastic packaging waste and more efficient use of resources. Another Directive named as the Waste Framework Directive (WFD 2008/98/EC) was issued in November 2008 to reduce the usage of landfills. This included quantifying targets for waste material recycling from households and other places. A green paper was also published for the management of Bio waste. According to this directive, members of the EU were 
required to prevent or reduce waste production and its harms, recovery of waste which includes recycling, reuse or using waste as a source of energy and as a final resort, a safe disposal (EC, 2008). The increase in the Greenhouse gas emissions and increased Global Warming have raised a lot of concerns. Due to these concerns, policy making is very much active in this regard. 15 members of the EU signed the KYOTO protocol under the United Nations Framework Convention on Climate Change and agreed to reduce on an average of $8 \%$ of its greenhouse gas emissions of 1990 in the period 20082012. Germany imposed a ban on landfilling of Organic waste in 1990 which has resulted in the lowest landfilling in the Whole Europe with a recycling rate of $87 \%$ as of now. Korean Government also imposed a ban on the landfilling of food waste in order to reduce leachate problems (Ministry of Environment, Korea). Since then food waste collecting and recycling centers have been promoted. As a result, food waste recycling facilities have increased. In countries that are developing, it is easy to find a regulating authority for handling electrical and electronic waste but little attention has been focused on plastic industry even though its adverse effects in the environment have been highlighted many times (Subramanian et al., 2014).

Similarly, in Pakistan, there are no laws present which prohibits the dumping of food waste in Landfills. Though independent companies like LWMC and OZ-Pak are working to reduce the municipal waste, but their recovery rates are very low.

The executives of both the companies were asked if they face any regulations by the government or any other agency to handle returns efficiently, make use of the returned material (recycling) and properly disposing them off. Majority of the participants had the same response. They said that they are not bounded by any such regulations. Government or any other agency has never asked to handle the returned items nor has provided any guidance about how to recycle or dispose them.

The table shown below represents that majority of the interviewees had the same response about Governmental Regulations. According to them, Government has never asked them to have a returns process and have not put any kind of charges on them if they do not handle returns in a way they should be handled. The table indicates the same thing. It can be seen that " 1 " is present in the "No Governmental Regulations" row, which indicates that out of six, five Interviewees said that they don't face any such regulations. One of the interviewees didn't give any response on it.

Table 2:Matrix coding for governmental regulations for RL

\begin{tabular}{|l|l|l|l|l|l|l|}
\hline & $\begin{array}{l}\text { Interview } \\
1\end{array}$ & $\begin{array}{l}\text { Interview } \\
2\end{array}$ & $\begin{array}{l}\text { Interview } \\
3\end{array}$ & $\begin{array}{l}\text { Interview } \\
4\end{array}$ & $\begin{array}{l}\text { Interview } \\
5\end{array}$ & $\begin{array}{l}\text { Interview } \\
6\end{array}$ \\
\hline $\begin{array}{l}\text { 1: No } \\
\text { Governmental } \\
\text { regulations }\end{array}$ & 1 & 1 & 0 & 1 & 1 & 1 \\
\hline $\begin{array}{l}\text { 2: Yes } \\
\text { Governmental } \\
\text { regulations }\end{array}$ & 0 & 0 & 0 & 0 & 0 & 0 \\
\hline
\end{tabular}

The model shown in table 2 also validates the above discussion. It can be seen that all 5 sources are being coded at the no regulations node. This indicates that all the 
interviewees have responded at the "NO Regulations" node. No source is coded the "YES Governmental Regulations" Node. This indicates the fact that the all interviewees said that they didn't face any regulations in regard of RL

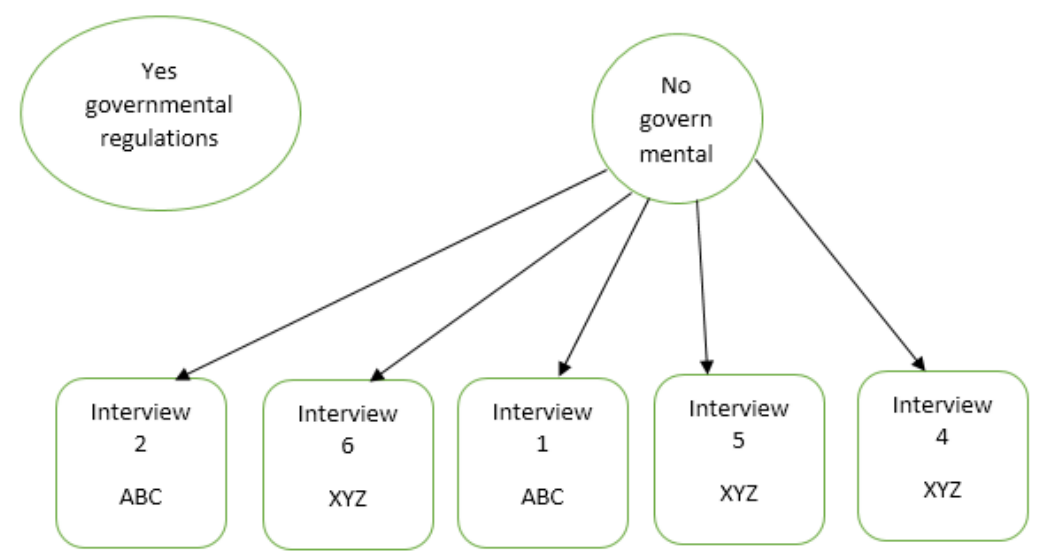

Figure 2: Source Coding for Governmental Regulations for RL

The executive of the companies was asked about their perception on the benefits of RL. Different people had different views on it. The NVIVO results are as follows:

Table 3:Matrix coding query for benefits of RL

\begin{tabular}{|l|l|l|l|l|l|l|}
\hline & $\begin{array}{l}\text { Interview } \\
1\end{array}$ & $\begin{array}{l}\text { Interview } \\
2\end{array}$ & $\begin{array}{l}\text { Interview } \\
3\end{array}$ & $\begin{array}{l}\text { Interview } \\
4\end{array}$ & $\begin{array}{l}\text { Interview } \\
5\end{array}$ & $\begin{array}{l}\text { Interview } \\
6\end{array}$ \\
\hline $\begin{array}{l}1 \text { Cost } \\
\text { efficiency }\end{array}$ & 0 & 1 & 0 & 0 & 1 & 0 \\
\hline $\begin{array}{l}2 \text { customer } \\
\text { satisfaction }\end{array}$ & 1 & 0 & 1 & 0 & 0 & 0 \\
\hline $\begin{array}{l}3 \\
\text { environmental } \\
\text { cleaning }\end{array}$ & 1 & 0 & 0 & 0 & 1 & 1 \\
\hline $\begin{array}{l}4 \text { scrutiny of } \\
\text { the process }\end{array}$ & 0 & 1 & 1 & 0 & 0 & 0 \\
\hline
\end{tabular}

This table shows the responses of people about the benefits that RL can provide. Out of six people, two people had the view that it can help increase the cost efficiency of the company. They were of the view that processes like recycling, reusing returned material could lower the costs. The other benefit identified by two out of six people was the customer satisfaction. They said that when a customer knows that the company quickly

Sukkur IBA Journal of Management and Business - SIJMB | Vol 6 No. 2 July - December 2019 @ Sukkur IBA University 
responds to the defected items and have a developed returns process, they are more inclined towards the company. They know that a company will not allow a defected item on the shelves and will remove it quickly. 3 people said that RL helps in the cleansing of environment. They said that when a company properly disposes of waste material responsibly and don't just throw them off, it helps to reduce the environmental pollution. Moreover, it helps in building a positive image of the company in the society. Two of the respondents said that this RL system can help to back track the original problems. When there is a proper system in place, the product moves back through a channel and the real problem is identified. It also lets us know how well the product is made. Basically, the data from the returns can help to identify the root cause of the problem and consequently could reduce the number of returns e.g. RL can help to know what the condition of an item is after a certain time or after passing through different conditions. It tells us that changes are needed to be done in the product. The Source coding for benefits of RL is given below:

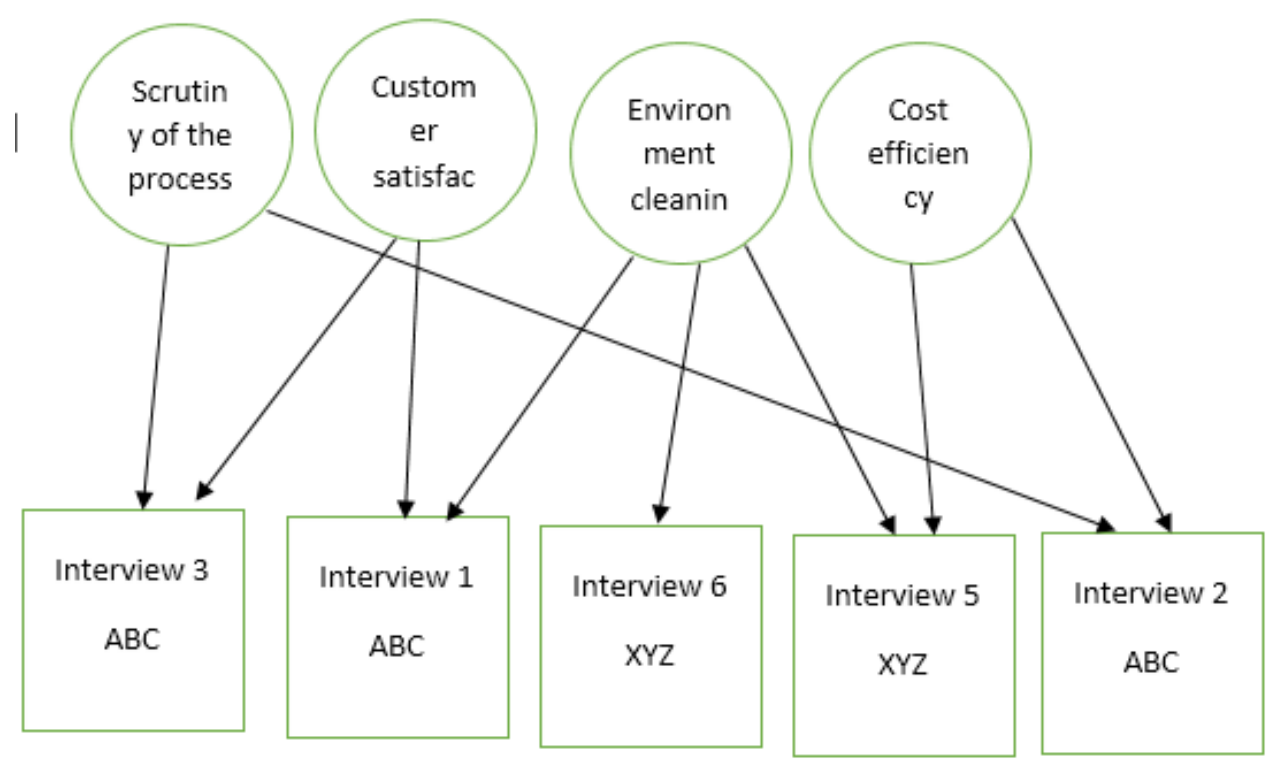

Figure 3: Source coding for benefits of RL

\section{Proposed framework for Reverse logistics}

As it has been mentioned in the literature that Returns Management is very much important for a company to ensure sustainability, our local companies are less aware of it. For a sustainable and economically feasible RL model collaboration between companies, governments and others, top management commitment is necessary (Lozano, 2008; Nagarajan et al.2013). Local food companies in Pakistan are unaware of the importance of Reverse Logistics. This is mainly due to the fact that there is less awareness on this topic. Moreover, companies do not consider it as an essential part of 
a sustainable supply chain. Companies are handling returns just for the sake of it. According to Cope (2007) the applicability of RL depends on how much the company is mature in terms of Reverse Logistics. According to Cope, there are five levels of maturity regarding RL. The first level is the innocence in which organizations have no knowledge about RL and do not perform RL activities at all. The second level is Understanding stage, in which organizations do have some knowledge about RL but are not performing RL activities efficiently. The third level is the Competence stage, in which organizations are able to execute RL activities quite successfully. The fourth level is the Development in which organizations try to gain excellence in RL activities and try to become a professional RL entity. The level five is the Excellence stage, in which the company becomes experts in RL. Referring to level of maturity given by Cope and based on the findings of this research, it can be concluded that the food companies under study are between stage one and stage two, which means that the companies are performing certain processes of RL but the process are poorly defined, proper guidelines are not present, no regard is given to the side effects of food and packaging waste and a further understanding of the process is required.

Based on the findings and literature review, the following model is being proposed, which can guide companies in the development and implementation of RL Process.

The model propose below comprises on two aspects. One is highlighting the importance of Reverse Logistics in Food Companies and the other is the way on how to implement Reverse Logistics in Food Companies.

Reverse Logistics should not be considered as an option but it should be considered as an essential part of the business process. Many a times companies consider RL to be an added self-burden while in reality it is a way to improve the business process. So before anything else, it should be find out what is the current state of knowledge about RL in the company. This could be done by asking the company executives about their concept of Reverse Logistics, how they are handling returns at the moment etc. If they know about RL then it is a good thing and one can go study the current practices and identify flaws in it and create solutions. If the company does not know about RL, first of all the companies should be made aware of what is RL and highlight its importance. This could be done by telling them how much adverse effects the waste created by their items can have on the environment. How much detrimental this waste could be for the environment as well as for their image. When a company does not fulfill its responsibility of dealing with the waste they have put forward, it gives a negative appearance of the company. People think that the company is not responsible enough as it does not take care for the environment or indirectly the company does not care for the consumers. 


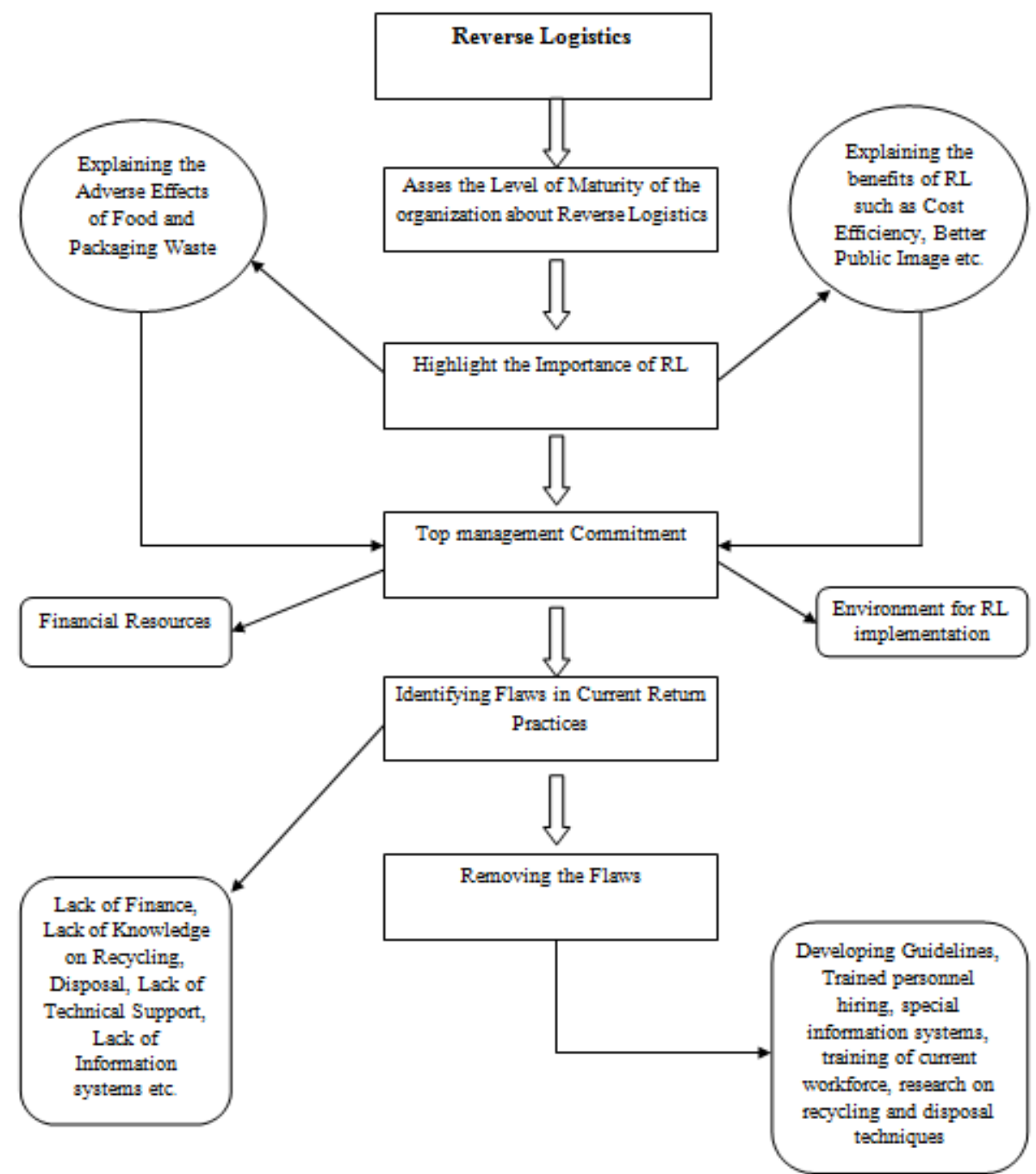

Figure 4: Framework for Highlighting the Importance and Implementation of RL

The next thing they should be made aware of is the financial gains that could be achieved through Reverse Logistics. The reuse or recycle of materials could result in a gain of value that would be otherwise lost if products are not recycled. The products could also be sold to secondary markets which is also a source of additional income. This could be done by educating them via seminars, lectures etc. this would lead to the change of the mindset of the organizations. They could be able to think RL to be a value-added activity rather than a burden.

After the importance of RL has been established, the next thing is the Implementation of Reverse Logistics. The first and foremost thing in this regard is the Top Management 
Commitment. This means that the management should acknowledge the importance and necessity of Reverse Logistics in Food Companies. The pre-requisite for this is to properly establish the importance because if the management does not know the value of Reverse Operation, they won't be engaged towards its implementation.

Once the management has understood the need for efficient Reverse Operations, The next step would be studying the current return practices (if any), identifying the costs associated with returns, identifying the flaws in the current returns process which may include no proper information systems, poor forecasting of returns, lack of departmental collaboration, lack of strategic planning, no awareness of recycling/ reusing options, no knowledge about proper disposal, lack of finance, no trained personnel for handling returns etc.

After the flaws have been identified in the current practices, the next step would be creating solutions to mitigate those flaws. This may include, but not restricted to, hiring experts of RL, training current workforce in RL activities, reserving fund for further research about reusing/recycling returned products and proper disposal, development of specialized systems, developing policies and guidelines for RL, timely information sharing among all the stakeholders.

It is also necessary that Government should also consider the importance of not handling returns and their consequences. Government should make strict laws which enforce the companies to deal with returns efficiently and in an environment friendly way. Government should make sure that the returns are not left unattended. Laws should make sure that the returned products are recycled/reused or if needed properly disposed off. Government should develop, with the help of experts, proper guidelines for recycling/reusing food waste as well as packaging waste. Companies should be asked to present annual or semiannual reports of the products that are returned and how they have been catered. Government should run educational programs to make the companies aware of the dangers of not handling returns. Consumers can also play an important role in the efficient handling and dealing of product returns. With their proper support, products could easily be reused and can be properly disposed.

\section{Conclusions}

This research focuses on the implementation of RL activities in two local food companies of Lahore. Reverse Logistics focuses on how the products are returned from the point of consumption to the point of origin with the aim of recapturing value by recycling/reusing or for the purpose of proper disposal. The study focuses on how food companies are handling returned items and what do these companies do with these items. Another aspect of this study is that what difficulties companies face while implementing Reverse Logistics process. Two local food companies were chosen to conduct the study. Both of the companies deal in same kind of items i.e., confectionary. Both of the companies use their forward logistics channels to bring the defected items back to the factory where they are treated.

The results of this study indicate that food companies are doing activities of RL in bits and pieces. No company has fully implemented the process of RL. The major reason is 
the lack of knowledge that companies have about RL and the absence of experts in the field. Since Company A has well established systems, they are properly disposing off the food returns (waste) into animal feed and as raw materials for Bio gas plants and giving back the packaging material to the plastic recycling companies but they still do not have any kind of mechanisms to gather the food waste or packaging material waste that occurs at the consumers' end. The company XYZ is still growing, it lacks proper system. People there are remotely aware of the implications for not having a RL process. They are indulged in recycling of returned items to make new food products, but they are not giving any kind of importance to the food items that cannot be recycled. They are not properly disposing them off. Same is the case with the packaging material, it is also thrown away without finding any proper solution. They are not considering the hazards and problems these wastes could create for the environment. Moreover, they are letting go off a great opportunity of gaining financial benefits. This can be attributed to the inattention of management towards Reverse Logistics. Another problem that was identified was the lack of Finance to hire experts for Reverse Logistics. The absence of laws for efficiently dealing with returns can also be considered a reason for companies not proficiently handling returns.

Having said that, following are some of the recommendations that could help companies with respect to Reverse Logistics

For the food and packaging waste created at the producers end, vacuum systems such as Mini vac could be placed separately which are connected to tanks and waste dealers take these tanks away.

For food and packaging waste produced at the consumers end, companies could ask the customers to drop the food and packaging waste next time they visit the shop. At the shops, these tanks could also be used.

The concept of Extended Producer Responsibility should be coined and enforced, according to which the producer of a certain product should take the responsibility of dealing with it after the end of its lifecycle. The proper methods for handling waste and disposing it off should be clearly mentioned on the packaging, to educate the community.

To increase the awareness about waste management behaviors and environment friendly attitudes, educational and awareness programs regarding the effects of food and packaging waste should be organized. Special training programs for workforce should be initiated, where workers should be taught how to handle returns based on the type of specific industry. Models should be developed for the collection of waste from consumers' place which ensure safe recovery along with cost efficiency. Specialized collection centers should be developed, where consumers can drop off waste items without any hassle.

Consumer credit schemes should be started to give compensations to consumers for delivering waste products or packaging materials to specialized centers. Special legislations should be made which enforces the food companies to effectively recycle the returned food items and packaging material. Food Companies can form coalition with companies like OZ-Pak, LSWN and can help them collect waste. Food companies 
in collaboration with these companies can arrange training for workers for proper segregating food waste from other types of waste and can provide innovative recycling options if possible. No food waste should be dumped off in the landfills rather it should be converted into feed for animals or plants.

This research can help companies operating in confectionary industry of Pakistan to monitor their processes and be aware of the challenges faced. Also, this research may be able to generalize some of the findings on its competitors however further research and analysis is needed so as to streamline processes and clear possible issues in the reverse logistics process.

\section{Limitations and Future Research}

The research was limited to only two companies due to the lack of resources of information. Most of the companies were hesitant in becoming the part of the study. The companies did not want to share their information. Even the companies under study were very much discreet. They did not provide any kind of documentary evidence due to which only personal observations had to be used as a tool for validity. The companies did not tell the names of the waste collectors and recycling companies with whom the companies were dealing with. The only sources of information were the interviews and personal observations. Furthermore, not much data is available on food waste in Pakistan. No previous information regarding Reverse Logistics in Food Companies in Pakistan is present at the moment.

Quantitative studies should be carried out in the future to have a broader view of the status of Reverse Logistics in Food Companies not only in Lahore but in the whole country across different cities highlighting the problems that companies face while implementing Reverse Logistics. Studies regarding new methods for dealing with returns should also be conducted. An intensive study should be carried out with a focus on collection of food waste from the consumers' place.

\section{References:}

Agarwal, V., Govindan, K., Darbari, J. D., \& Jha, P. C. (2016). An optimization model for sustainable solutions towards implementation of reverse logistics under collaborative framework. International Journal of System Assurance Engineering and Management, 480-487.

Chan, F. T., \& Chan, H. K. (2008). A survey on reverse logistics system of mobile phone industry. Management Decision, 702-708.

Corvellec, H., \& Hultman, J. (2012). From "less landfilling" to "wasting less" : Societal narratives, socio-materiality, and organizations . Journal of Organizational Change Management, 297 - 314.

Darkow, I.-L., A. von der Gracht, H., \& Foerster, B. (2015). Sustainability in food service supply chains: future expectations from European industry experts toward the environmental perspective. Supply Chain Management: An International Journal, 163 - 178. 
Department for Communities and Local Government, UK. (2014). Recycling Reward Scheme 2015-16. Department for Communities and Local Government, UK.

Frenkel, V. S., Cummings, G., Scannell, D. E., Tang, W. Z., \& Maillacheruvu, K. Y. (2008). Food-Processing Wastes. Water Environment Research, 1458-1480.

Grandhi, B., \& Singh, J. A. (2016). What a Waste! A Study of Food Wastage Behavior in Singapore. Journal of Food Products Marketing, 471-485.

Helmi Ali, M., Hua Tan, K., \& Daud Ismail, M. (2017). A supply chain integrity framework for halal food. British Food Journal, 20 - 38.

Hopewell, J., Dvorak, R., \& Kosior, E. (2009). Plastics Recycling: Challenges and Opportunities. Philosophical Transactions: Biological Sciences, Vol. 364, No. 1526, Plastics, the Environment and Human Health, 21152126.

Huscroft, J. R., Hazen, B. T., Hall, D. J., Skipper, J. B., \& Hanna, J. B. (2013). Reverse logistics: past research, current management issues and future directions. The International Journal of Logistics Management, 304 327.

(2011). IKEA saves money through instore food recycling scheme. Zero Waste Scotland.

Jaaron, A. A., \& Backhouse, C. (2016). A systems approach for forward and reverse logistics design Maximising value from customer involvement. The International Journal of Logistics Management, 947 - 971.

Jalil, E. E., Grant, D. B., Nicholson, J. D., \& Deutz, P. (2016). Reverse logistics in household recycling and waste systems: a symbiosis perspective. Supply Chain Management: An International Journal, 245 - 258.

Ju, M., Bae, S.-J., Young Kim, J., \& Hoon Lee, D. (2016). Solid recovery rate of food waste recycling in South Korea. J Mater Cycles Waste Management, 419-426.

Kim, M. H., Song, H. B., Song, Y., Jeong, I. T., \& Kim, J. W. (2013). Evaluation of food waste disposal options in terms of global warming and energy recovery: Korea. International Journal of Energy and Environmental Engineering.

Kjær, B. (2013). Municipal waste management in Denmark. European Environment Agency.

Lanfranchi, M., Calabrò, G., \& De Pascale, A. (2016). Household food waste and eating behavior: empirical survey. British Food Journal, 3059 - 3072. 
M. C. Lo, I., \& Woon, K. S. (2016). Food waste collection and recycling for value-added products:potential applications and challenges in Hong Kong. Evironmental Science Pollution resolution, 7081-7091.

Maloni, M. J., \& Brown, M. E. (2006). Corporate Social Responsibility in the Supply Chain: An Application in the Food Industry. Journal of Business Ethics, 35-52.

Mathew, V., \& Rodrigues, G. (2011). EnviroServe: The Green Company. Emerald Emerging Markets Case Studies, 1 - 13.

Nilsson, F., \& Abbasi, M. (2012). Themes and challenges in making supply chains environmentally sustainable. Supply Chain Management: An International Journal, 517-530.

Olorunniwo, F., \& Li, X. (2008). An exploration of reverse logistics practices in three companies. Supply Chain Management: An International Journal, $381-386$.

Parfitt, J., Barthel, M., \& Macnaughton, S. (2010). Food waste within food supply chains: quantification and potential for change to 2050. Philosophical Transactions: Biological Sciences, 3065-3081.

R. Skinner, L., T. Bryant, P., \& Glenn Richey, R. (2008). Examining the impact of reverse logistics disposition strategies. International Journal of Physical Distribution \& Logistics Management, 518 - 539.

Rahimifard, S., Coates, G., Staikos, T., Edwards, C., \& Abu-Bakar, M. (2009). Barriers, drivers and challenges for sustainable product recovery and recycling. International Journal of Sustainable Engineering, 80-90.

Ravi, V., \& Shankar, R. (2015). Survey of reverse logistics practices in manufacturing industries: an Indian context. Benchmarking: An International Journal, 874 - 899.

Riikka, K., Dukovska-Popovska, I., \& Loikkanen, L. (2013). Creating sustainable fresh food supply chains through waste reduction. International Journal of Physical Distribution \& Logistics Management, 262 - 276.

Rossi, S., Bernon, M., \& Cullen.John. (2011). Retail reverse logistics: a call and grounding framework for research. International Journal of Physical Distribution \& Logistics Management, 484-510.

(2013). Waste Management Plan for England. Department for Environement, food and rural affairs, UK. 